\title{
Short communication: Urea transporter protein UT-B in the bovine parotid gland
}

\author{
L. Dix, ${ }^{*}$ D. T. Ward, $†$ and G. S. Stewart*1 \\ *School of Biology and Environmental Science, College of Life Sciences, University College Dublin, Belfield, Dublin 4, Ireland \\ †Faculty of Life Sciences, Michael Smith Building, Oxford Road, University of Manchester, United Kingdom
}

\begin{abstract}
Ruminant nutrition relies upon the symbiotic relationship that exists with microbial populations in the rumen. Urea transported across the ruminal epithelia and secreted by the salivary glands is a key source of nitrogen for microbial growth in the rumen. As ruminal urea transport can be mediated by specific UT-B urea transporters, this study investigated whether UT-B urea transporters were also present in the bovine salivary gland. Western blotting experiments detected only small amounts of UT-B protein in whole-cell lysate from the bovine parotid gland. In contrast, strong 32 to 34 and $40 \mathrm{kDa}$ UT-B proteins were detected in parotid plasma membrane-enriched protein, showing the importance of using enriched samples. These signals were also detected in rumen and correspond to bovine UT-B1 and UT-B2 urea transporters, respectively. Further immunolocalization studies identified that these proteins were located in the ductal system of the parotid gland. This study, therefore, confirmed the presence of UT-B urea transporter protein in the bovine parotid salivary gland.
\end{abstract}

Key words: parotid, urea, UT-B transporter, plasma membrane

\section{Short Communication}

Ruminant nutrition relies on the symbiotic relationship that exists with the microbial populations that reside in their gastrointestinal tract, particularly in the rumen. Urea is the main breakdown product of protein catabolism produced in the mammalian liver, and is a key source of nitrogen for ruminal microbial protein synthesis (Lapierre and Lobley, 2001). Regulated movement of urea from the ruminant bloodstream into the rumen is believed to mainly occur via facilitative UT-B urea transporters located in the ruminal papillae epithelial layers (Stewart et al., 2005). Ruminal UT-B

Received October 4, 2012.

Accepted December 5, 2012.

${ }^{1}$ Corresponding author: gavin.stewart@ucd.ie transporters have been reported in various species - including cow (Marini and Van Amburgh, 2003), sheep (Ludden et al., 2009), and goat (Muscher et al., 2010)and shown to be regulated by DM intake (Simmons et al., 2009). Recent studies have also shown that UT-B mRNA expression level increases markedly within the developing bovine rumen in correlation with increases in blood urea levels (Naeem et al., 2012). Urea recycling throughout the bloodstream is also facilitated by dietary regulation of urea transporters in the kidneys, as reported in various ruminants - sheep (Artagaveytia et al., 2005), cow (Simmons et al., 2009), and goat (Starke et al., 2012).

Importantly, salivary urea contributes between 10 and $40 \%$ of ruminal urea entry, with the extent of its contribution dependent on DM intake (Lapierre and Lobley, 2001). Although it has been reported that salivary urea reflects plasma urea concentration in a wide range of mammals - for example, sheep (Warner and Stacy, 1977), dogs (Watanabe et al., 1984), and humans (Gilman et al., 1981) - a recent investigation of urea transport into goat saliva suggested the involvement of a transporter-mediated mechanism (Muscher et al., 2010). Indeed, it has previously been reported that UT-B protein is present in the parotid salivary glands of lambs (Ludden et al., 2009). As the extent of urea recycling into the rumen varies between ruminants (Lapierre and Lobley, 2001), it is important to determine UT-B expression in the digestive system in each species. Our hypothesis was that bovine salivary gland tissue expresses UT-B urea transporters. The objective of this short study was to investigate for the presence of UT-B transporters in the bovine parotid salivary gland.

Bovine whole cell lysate protein samples for parotid, rumen, small intestine, and colon were purchased from Novus Biologicals (Cambridge, UK) and AMS Biotechnology (Abingdon, UK), and then combined with Laemmli buffer. Bovine parotid salivary gland and rumen tissue samples were obtained from commercial slaughterhouses and excised within $1 \mathrm{~h}$ of slaughter. Tissue samples were dissected into small pieces, placed into cold homogenization buffer (300 $\mathrm{m} M$ mannitol, $12 \mathrm{~m} M$ HEPES, $\mathrm{pH}$ 7.6) and homogenized with a 
PT1200E Polytron homogenizer (Kinematica AG, Lucerne, Switzerland) for $30 \mathrm{~s}$. For rumen samples, these laboratory-prepared, whole-cell homogenates were centrifuged at $2,000 \times g$ for $10 \mathrm{~min}$ at $4^{\circ} \mathrm{C}$ to remove nuclei and any remaining tissue fragments. The resultant supernatant was centrifuged at $16,300 \times g$ for 30 min at $4^{\circ} \mathrm{C}$. The resulting pellet formed was enriched for plasma membrane protein, whereas the remaining supernatant was enriched for cytoplasmic contents. These different samples were separately resuspended in a homogenization buffer. For parotid samples the same protocol was followed, except the second centrifugation step, which was at $100,000 \times g$ for $30 \mathrm{~min}$ at $4^{\circ} \mathrm{C}$. In deglycosylation experiments, protein samples were further incubated for $1 \mathrm{~h}$ at $37^{\circ} \mathrm{C}$ with or without the presence of $N$-linked-glycopeptide-( $N$-acetyl- $\beta$-D-glucosaminyl)L-asparagine amidohydrolase (PNGaseF) enzyme (New England Biolabs, Hitchin, UK). Finally, samples were combined with $2 \times$ Laemmli buffer to make final protein samples of approximately $1 \mu \mathrm{g} / \mu \mathrm{L}$. Using these samples, SDS-PAGE was performed on minigels of $12 \%$ polyacrylamide by loading $\sim 20 \mu \mathrm{g}$ of protein per lane. Western blotting experiments were then performed following a previously described protocol and using a characterized UT-B antibody (i.e., the BUTBPAN antibody that was raised against the last 19 AA amino acids of the C-terminal of bovine UT-B: EENRIFYLQSRKRTVQGPL; Simmons et al., 2009). To investigate specificity of any parotid signals obtained, a Western blot was also performed using BUTB-PAN that had been preincubated with $1 \mu \mathrm{g} / \mathrm{mL}$ of the original immunizing peptide for $6 \mathrm{~h}$ at room temperature in a rotating shaker. Finally, a separate control Western blot for GAPDH was performed using the same protein samples and the Y3322GAPDH monoclonal antibody (AMS Biotechnology). For immunolocalization studies, bovine parotid salivary glands were immersion-fixed overnight in ice-cold 3\% paraformaldehyde in PBS and then incubated for a further $24 \mathrm{~h}$ in $30 \%$ sucrose/ PBS at $4^{\circ} \mathrm{C}$. The parotid tissue was then embedded in optimum cutting temperature compound (Tissue-Tek, Sakura, Alphen aan den Rijn, the Netherlands) and cryo-sectioned into $10-\mu \mathrm{m}$ sections. These sections were put on slides and UT-B immunolocalization studies were performed using the BUTB-PAN antibody and a well-established staining protocol (Simmons et al., 2009).

Using purchased whole-cell lysate samples (Novus Biologicals), strong, 30 to $34 \mathrm{kDa}$ UT-B protein signals were detected only in the bovine rumen sample (Figure 1A), whereas a $38 \mathrm{kDa}$ GAPDH signal was detected in all samples tested. Importantly, no signals were detected after preincubation of UT-B antibody with the original immunizing peptide (Figure 1A). In contrast, strong UT-B signals were detected in both rumen and small intestine whole-cell lysates purchased from AMS Biotechnology (Figure 1B). In the parotid whole-cell lysate deglycosylation experiment, only very weak signals were detected (Figure 2). In contrast, a strong, 32 to $34 \mathrm{kDa}$ signal in 2 different rumen samples was deglycosylated to a $\sim 29 \mathrm{kDa}$ protein, whereas a $30 \mathrm{kDa}$ signal remained unchanged. Finally, a moderate, $32 \mathrm{kDa}$ signal in the small intestine sample was also deglycosylated to a $29 \mathrm{kDa}$ protein, whereas no signals were detected in the colon. Compared with the whole-cell lysate, a plasma membrane-enriched bovine parotid sample produced much stronger UT-B signals (Figure 3). A strong, 32 to $34 \mathrm{kDa}$ signal was now detectable and partially deglycosylated to $\sim 30 \mathrm{kDa}$, whereas a $40 \mathrm{kDa}$ signal remained unchanged. In a rumen plasma membrane-enriched sample, a similar 32 to $34 \mathrm{kDa}$ signal also partially deglycosylated to $\sim 30 \mathrm{kDa}$. Deglycosylation of a moderate, 40 to $55 \mathrm{kDa}$ smear toward a single $40 \mathrm{kDa}$ protein was also observed. In contrast, only a strong, unglycosylated $30 \mathrm{kDa}$ protein was present in the cytoplasmic content-enriched rumen sample. Finally, immunolocalization studies showed UT-B protein was localized to specific regions of the bovine parotid salivary gland (Figure 4). Strong UT-B staining was observed primarily in epithelial cells that lined the main (Figure 4A), interlobular (Figure 4B), and intralobular ducts (Figure 4C).

Using whole-cell lysates, initial Western blotting experiments detected the strongest UT-B signals in the rumen (Figure 1), as previously reported (Simmons et al., 2009), but with only very weak signals in the parotid gland. Interestingly, UT-B protein was variable in small intestine samples and absent from colon, in contrast to reported human colonic UT-B expression (Collins et al., 2010). Two distinct bovine (b) UT-B isoforms (bUT-B1 and bUT-B2) have previously been identified (Stewart et al., 2005), and the 32 to $34 \mathrm{kDa}$ rumen protein represents glycosylated bUT-B1 (Simmons et al., 2009). In contrast, using plasma membrane-enriched samples revealed much stronger UT-B signals in the parotid gland (Figure 3), with the 32 to $34 \mathrm{kDa}$ glycosylated bUT-B1 protein clearly visible. An additional, unglycosylated $40 \mathrm{kDa}$ UT-B protein was also present, and was similar in size to that previously reported for unglycosylated bUT-B2 (Simmons et al., 2009). It is interesting to note that rumen plasma membrane contained a 40 to 55 $\mathrm{kDa}$ signal that deglycosylated to $40 \mathrm{kDa}$, which probably represented glycosylated UT-B2. Indeed, we have previously reported bUT-B2 to be located in plasma membrane-enriched samples (Tickle et al., 2009). In contrast, only an unglycosylated $30 \mathrm{kDa}$ protein was present in the rumen cytoplasm. Importantly, although not clearly understood for UT-B proteins (Stewart, 

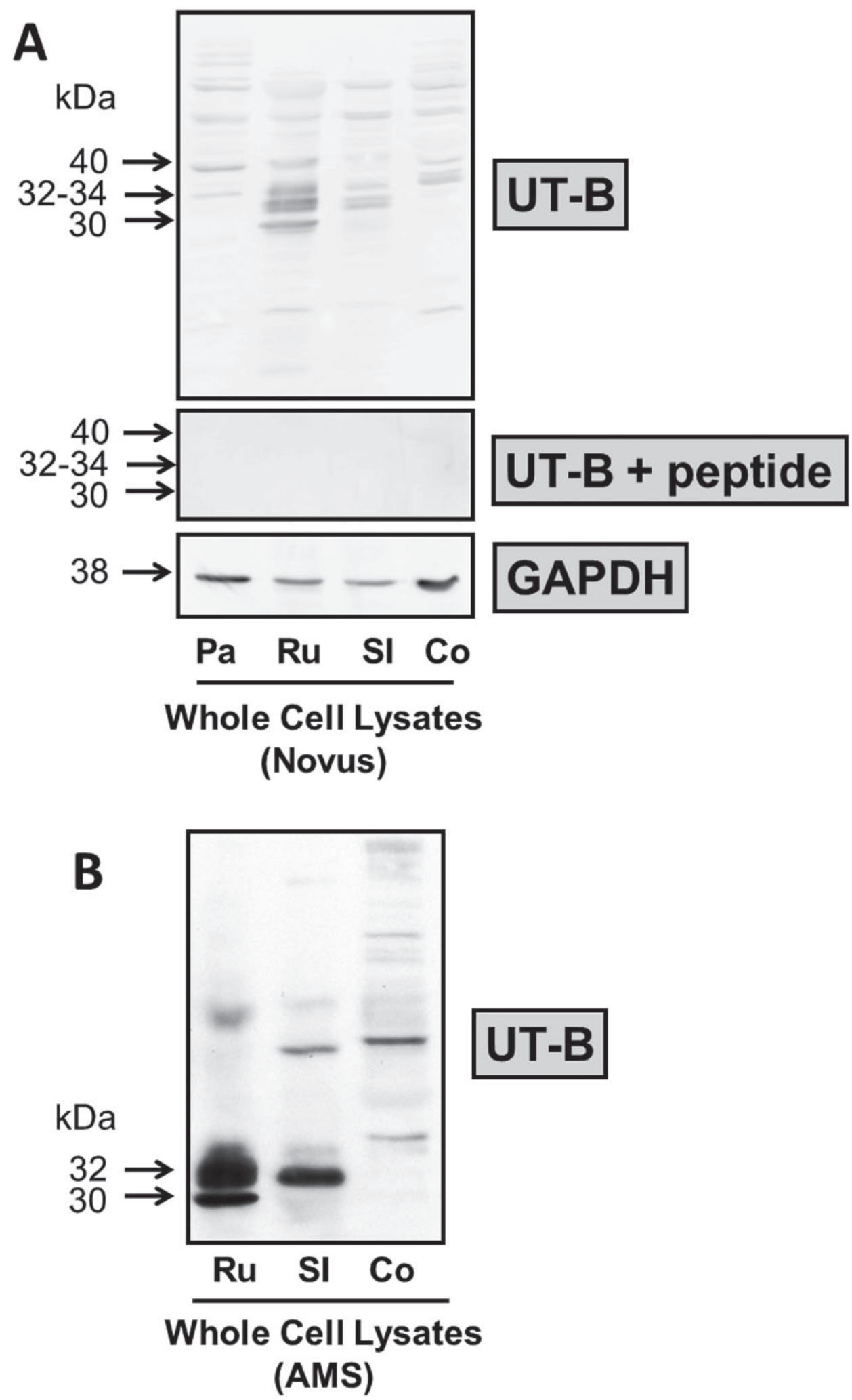

Figure 1. (A) Western blots comparing urea transporter UT-B and GAPDH protein abundance in whole-cell lysate samples (Novus Biologicals, Cambridge, UK) from the bovine digestive system. (B) Western blots showing UT-B protein abundance in similar whole-cell lysate samples obtained from a different source (AMS Biotechnology, Abingdon, UK). Pa = parotid salivary gland; Ru = rumen; SI = small intestine; $\mathrm{Co}=$ colon; UT-B + peptide $=\mathrm{UT}-\mathrm{B}$ primary antibody preincubated with $1 \mu \mathrm{g} / \mathrm{mL}$ specific peptide for $6 \mathrm{~h}$. 


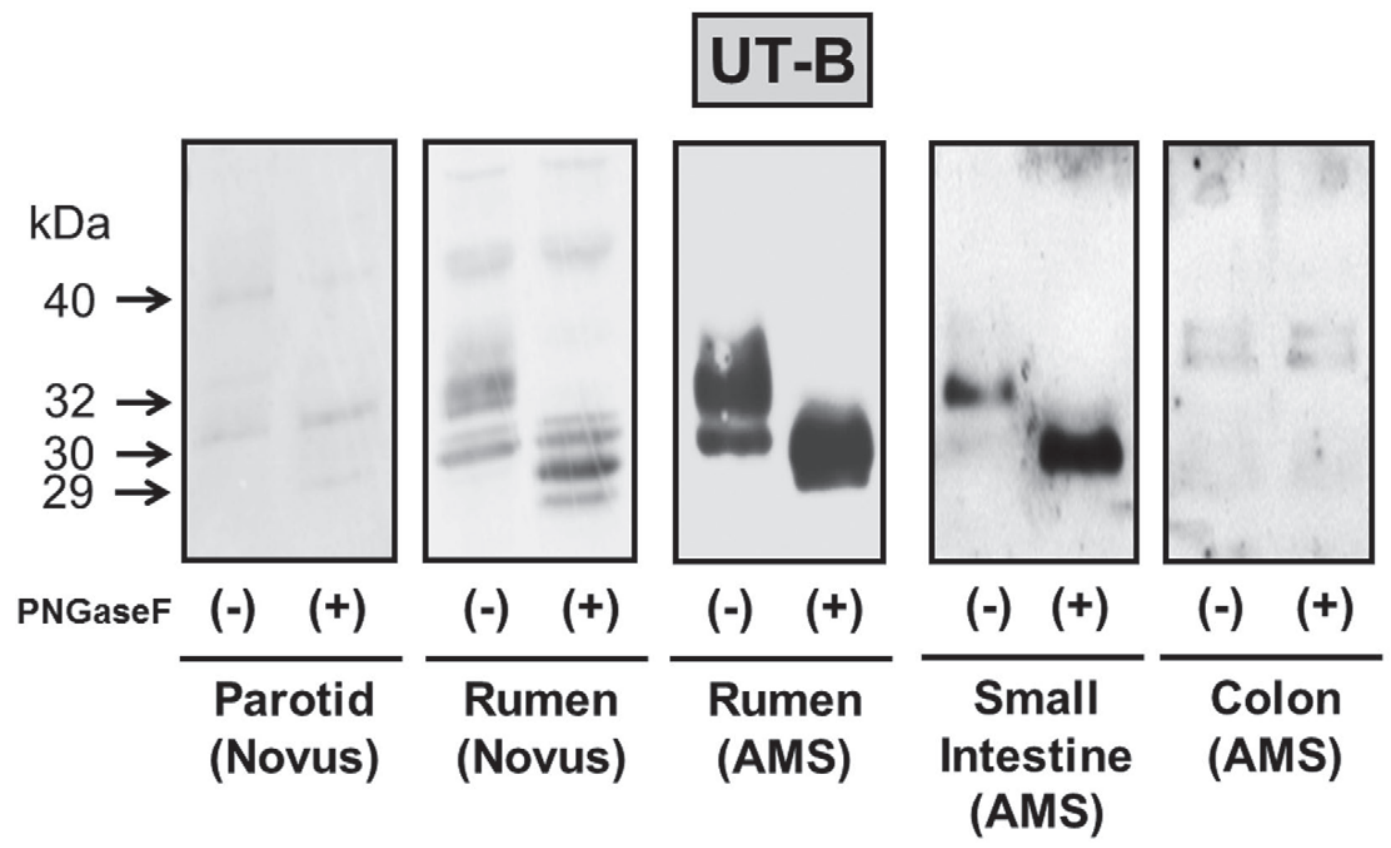

Figure 2. Western blots investigating deglycosylation of UT-B proteins in whole-cell lysate samples [from Novus Biologicals (Cambridge, UK) and AMS Biotechnology (Abingdon, UK) $]$ from the bovine digestive system. $-=$ no PNGaseF $[N$-linked-glycopeptide- $(N$-acetyl- $\beta$-Dglucosaminyl)-L-asparagine amidohydrolase] enzyme treatment; + = incubated in PNGaseF enzyme for $1 \mathrm{~h}$ at $37^{\circ} \mathrm{C}$.

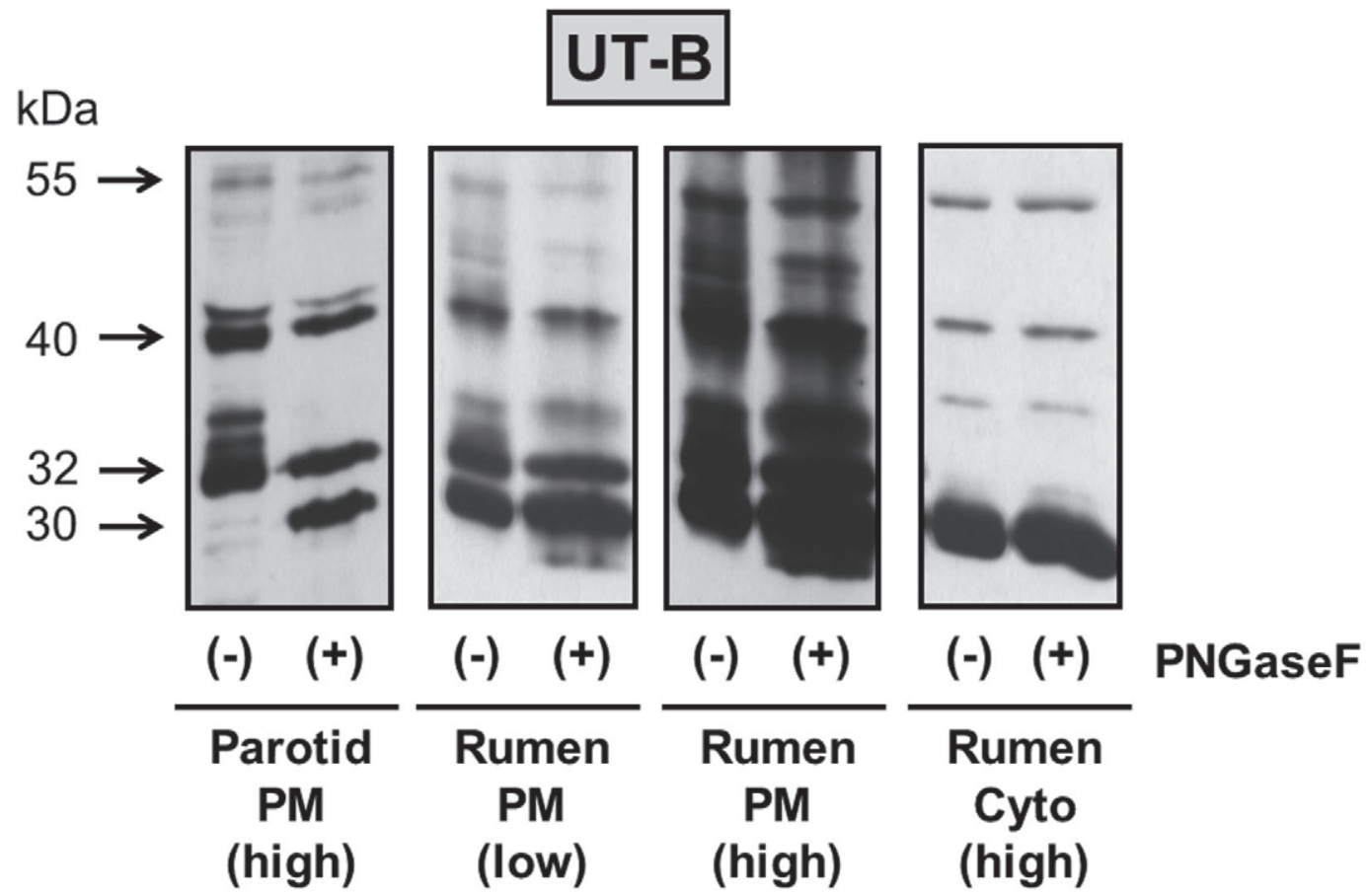

Figure 3. Western blots investigating deglycosylation of UT-B proteins in plasma membrane-enriched protein samples from bovine parotid salivary gland and rumen. $-=$ no PNGaseF [ $N$-linked-glycopeptide-( $N$-acetyl- $\beta$-D-glucosaminyl)-L-asparagine amidohydrolase] enzyme treatment; + = incubated in PNGaseF enzyme for $1 \mathrm{~h}$ at $37^{\circ} \mathrm{C}$; $\mathrm{PM}=$ plasma membrane-enriched sample; Cyto = cytoplasm-enriched sample; low = image exposure taken after $1 \mathrm{~min}$; high = image exposure taken after $2 \mathrm{~min}$. 
UT-B

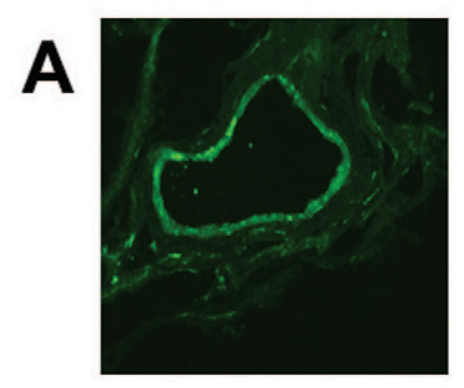

Main duct
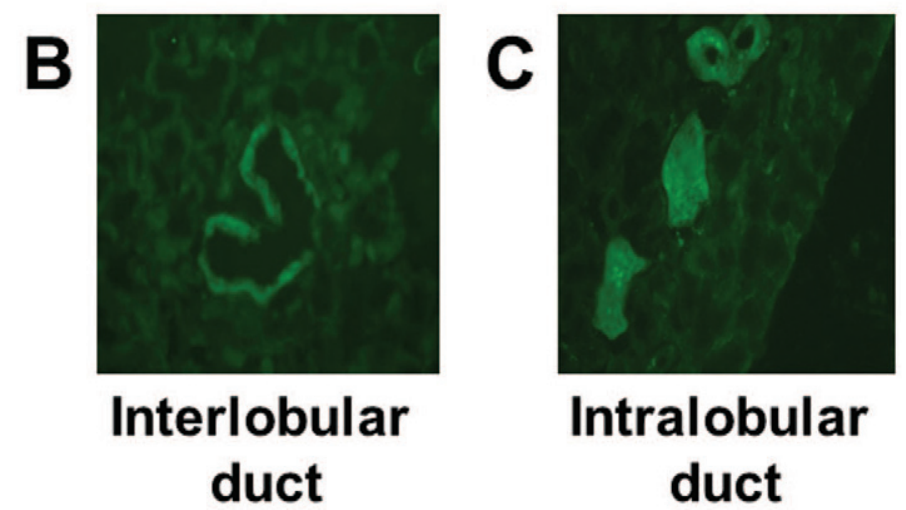

Figure 4. Immunolocalization of urea transporter UT-B in the bovine parotid salivary gland, showing (A) a main duct (10× magnification), (B) an interlobular duct (25× magnification), and (C) an intralobular duct ( $25 \times$ magnification). Color version available in the online PDF.

2011), recent research has confirmed that glycosylation plays a crucial role in plasma membrane stability and transport function of another type of urea transporters - the renal UT-A proteins (Su et al., 2012). Our results, therefore, show the importance of using plasma membrane-enriched protein, rather than whole-cell proteins or RNA, when studying UT-B in ruminants. Indeed, the use of different techniques may explain the discrepancy in the literature regarding effects of dietary intake on ruminal UT-B, where some studies have observed changes (Ludden et al., 2009; Simmons et al., 2009), whereas others have not (Røjen et al., 2011a,b). It is appropriate to note that another factor involved in this discrepancy could be the different developmental stages of animals investigated, as this is now known to affect UT-B expression (Naeem et al., 2012).

Finally, immunolocalization experiments clearly showed that UT-B was confined to the ductal system of the bovine parotid salivary gland (Figure 4 ). The simplest hypothesis would be that UT-B helps mediate urea secretion from the bloodstream into the bovine saliva. However, a previous functional study performed in dogs suggested that urea can actually be reabsorbed in the mandibular striated duct (Watanabe et al., 1986). This finding suggests that UT-B could also function in the reabsorption of urea from saliva, but further functional studies studying the precise role of UT-B in saliva production are now urgently required. However, it should be noted that extensive inhibition of bUT-B function has previously been reported with 1,3-dimethylurea but not with phloretin (Tickle et al., 2009). Phloretin, a nonspecific compound that has been used in ruminal urea transport studies in the past with limited success (Stew- art et al., 2005; Doranalli et al., 2011), may therefore not be suitable for investigating UT-B function in certain ruminant species. It should also be noted that both salivary and serum urea concentrations greatly fluctuate on a daily basis (Piccione et al., 2006), having important implications for all sampling protocols used in dietary studies investigating parotid urea transport function.

Previous studies have shown that parotid UT-B protein in lambs was unaffected by dietary nitrogen intake (Ludden et al., 2009), whereas changes in nitrogen intake had no clear effect on salivary urea transport in goats, but did affect ruminal transport (Muscher et al., 2010). As the contribution of saliva to ruminal urea entry has been shown to alter with diet (Lapierre and Lobley, 2001), this suggests that salivary urea transport is generally constant (compare to ruminal urea transport). However, it has also been noted that urea secretion from the parotid salivary gland in sheep can be directly regulated by changes in the osmotic pressure (Warner and Stacy, 1977) or urea concentration (Obara and Shimbayashi, 1979) of the rumen contents. Because this study has shown that both bovine parotid and rumen samples contain bUT-B1 and bUT-B2 proteins, with varying degrees of glycosylation, it further suggests at least the potential for regulation of urea transport in both tissues. Future studies investigating the potential role of UT-B in ruminant nitrogen recycling should therefore consider (1) changes in both general protein expression levels and in glycosylation state, and (2) that the key tissues to study include rumen, kidneys, and the parotid salivary gland.

In conclusion, this study showed that bovine parotid salivary glands express UT-B urea transporter protein. 
It also highlighted the importance of using the appropriate techniques when investigating UT-B in ruminants. We propose that researchers in this field study effects on plasma membrane-enriched protein, rather than whole-cell proteins or RNA. Indeed, the use of different techniques may explain the discrepancies in the current literature regarding the effects of changing dietary intake on ruminal UT-B expression.

\section{ACKNOWLEDGMENTS}

This work was funded with the help of The Royal Society (London, UK) and University College Dublin (Ireland).

\section{REFERENCES}

Artagaveytia, N., J. M. Elalouf, C. de Rouffignac, R. Boivin, and A. Cirio. 2005. Expression of urea transporter (UT-A) mRNA in papilla and pelvic epithelium of kidney in normal and low protein fed sheep. Comp. Biochem. Physiol. B Biochem. Mol. Biol. 140:279-285.

Collins, D., D. C. Winter, A. M. Hogan, L. Schirmer, A. W. Baird, and G. S. Stewart. 2010. Differential protein abundance and function of UT-B urea transporters in human colon. Am. J. Physiol. Gastrointest. Liver Physiol. 298:G345-G351.

Doranalli, K., G. B. Penner, and T. Mutsvangwa. 2011. Feeding oscillatory dietary crude protein concentrations increases nitrogen utilization in growing lambs and this response is partly attributable to increased urea transfer to the rumen. J. Nutr. 141:560-567.

Gilman, S. C., R. J. Biersner, and L. W. Mooney. 1981. A noninvasive technique for monitoring blood urea in humans during hyperbaric exposure. Aviat. Space Environ. Med. 52:392-393.

Lapierre, H., and G. E. Lobley. 2001. Nitrogen recycling in the ruminant: A review. J. Dairy Sci. 84(E. Suppl.):E223-E236.

Ludden, P. A., R. M. Stohrer, K. J. Austin, R. L. Atkinson, E. L. Belden, and H. J. Harlow. 2009. Effect of protein supplementation on expression and distribution of urea transporter B in lambs fed low quality forage. J. Anim. Sci. 87:1354-1365.

Marini, J. C., and B. E. Van Amburgh. 2003. Nitrogen metabolism and recycling in Holstein heifers. J. Anim. Sci. 81:545-552.

Muscher, A. S., B. Schroder, G. Breves, and K. Huber. 2010. Dietary nitrogen reduction enhances urea transport across goat rumen epithelium. J. Anim. Sci. 88:3390-3398.
Naeem, A., J. K. Drackley, J. Stamey, and J. J. Loor. 2012. Role of metabolic and cellular proliferation genes in ruminal development is response to enhanced plane of nutrition in neonatal Holstein calves. J. Dairy Sci. 95:1807-1820.

Obara, Y., and K. Shimbayashi. 1979. Intraruminal injection of urea and changes in secretion of parotid saliva in sheep. Br. J. Nutr. 42:497-505.

Piccione, G., A. Foa, C. Bertolucci, and G. Caola. 2006. Daily rhythm of salivary and serum concentration of sheep. J. Circadian Rhythms 4:16-19.

Røjen. B. A., P. K. Theil, and N. B. Kristenesen. 2011a. Effects of nitrogen supply on inter-organ fluxes of urea $\mathrm{N}$ and renal urea $\mathrm{N}$ kinetics in lactating Holstein cows. J. Dairy Sci. 94:2532-2544.

Røjen, B. A., S. B. Poulsen, P. K. Theil, R. A. Fenton, and N. B. Kristensen. 2011b. Short communication: Effects of dietary nitrogen concentration on messenger RNA expression and protein abundance of urea transporter B and aquaporins in ruminal papillae from lactating Holstein cows. J. Dairy Sci. 94:2587-2591.

Simmons, N. L., A. S. Chaudhery, C. Graham, E. S. Scriven, A. Thistlethwaite, C. P. Smith, and G. S. Stewart. 2009. Dietary regulation of ruminal bovine UT-B urea transporter expression and localization. J. Anim. Sci. 87:3288-3299.

Starke, S., A. S. Muscher, N. Hirschhausen, E. Pfeffer, G. Breves, and K. Huber. 2012. Expression of urea transporters is affected by dietary nitrogen restriction in goat kidney. J. Anim. Sci. 90:38893897

Stewart, G. 2011. The emerging physiological roles of the SLC14A family of urea transporters. Br. J. Pharmacol. 164:1780-1792.

Stewart, G. S., C. Graham, S. Cattell, T. P. Smith, N. L. Simmons, and C. P. Smith. 2005. UT-B is expressed in bovine rumen: Potential role in ruminal urea transport. Am. J. Physiol. Regul. Integr. Comp. Physiol. 289:R605-R612.

$\mathrm{Su}, \mathrm{H}$., C. B. Carter, O. Frohlich, R. D. Cummings, and G. Chen 2012. Glycoforms of UT-A3 urea transporter with poly- $N$-acetyllactosamine glycosylation have enhanced transport activity. Am. J. Physiol. Renal Physiol. 303:F201-F208.

Tickle, P., A. Thistlethwaite, C. P. Smith, and G. S. Stewart. 2009 Novel bUT-B2 urea transporter isoform is constitutively activated. Am. J. Physiol. Regul. Integr. Comp. Physiol. 297:R323-R329.

Warner, A. C., and B. D. Stacy. 1977. Influence of ruminal and plasma osmotic pressure on salivary secretion is sheep. Q. J. Exp. Physiol. Cogn. Med. Sci. 62:133-142.

Watanabe, J., S. Mizuno, K. Iwamoto, and S. Ozeki. 1986. Role of mandibular striated duct in salivary excretion of urea in dogs. J. Pharmacobiodyn. 9:197-201.

Watanabe, J., S. Mizuno, N. Masuda, Y. Hayashi, K. Iwamoto, J. Hirate, and S. Ozeki. 1984. Salivary excretion of urea in dogs. J. Pharmacobiodyn. 7:294-303. 